Life, the Universe and anything goes

Robert Shapiro

Our Place in the Cosmos. By Fred Hoyle and Chandra Wickramasinghe. Dent: 1993. Pp. 190. £16.99.

IMAGINE that the cosmos teems with life, of a kind similar in biochemistry to our own. Not only are Earth-like planets inhabited, but comets and gas giants as well. Further, the interstellar clouds are composed of frozen bacteria. Life on Earth began when a life-bearing comet arrived from outer space. Further deliveries over several thousand million years have brought viruses, bacteria and even bees here, as a driving force for evolution (Darwin was wrong). All the genes needed for the development of animal life, including our own intellects, arrived in a massive immigration from space 570 million years ago, and waited for a suitable opportunity to express themselves. More recent deliveries have had less kind effects, such as the extinction of the dinosaurs and the initiation of epidemics of bubonic plague, influenza and other diseases.

If this scenario does not strike you as plausible, then you are not alone. For more than a decade, Sir Fred Hoyle and Chandra Wickramasinghe have argued the above to be true in a succession of books (Our Place in the Cosmos is the latest) and converted, to my knowledge, no one at all. I choose the word 'converted' with care, for the authors present their case with a degree of inner certainty and in a polemic style that would make a cult leader gnash his (or her) teeth with envy. Their own views are based on evidence that they believe "is irrefutable", while opposing theories are based on "dogma", "without any tangible proof or evidence", and perpetuated by a "cabal" that controls the scientific journals.

This style permeates the presentation, which almost lacks references and is based to a good extent on flawed comparisons and unjustified associations and extrapolations. For example, an almost featureless area of the infrared spectrum from a cosmic source (it contains only broad humps suggesting the presence of $\mathrm{C}-\mathrm{N}, \mathrm{N}-\mathrm{H}$ and $\mathrm{O}-\mathrm{H}$ bonds) is used for an exact identification: "The correspondences between our model and the data are so precise that we have been encouraged to suggest that cosmic dust grains are indeed bacteria". In earlier studies the authors had suggested, with some confidence, that the grains were a silicategraphite mixture, polyoxymethylene, a mixture of organic polymers, sporopollenin, cellulose, a mixture of polysac- charides, and then a polysaccharidehydrocarbon mixture. They do not like to leave a problem unresolved.

Other arguments are weaker still. The ability of bacteria to repair damage inflicted by short-wavelength radiation is cited as proof of their extraterrestrial origins (one might argue as well that their ability to remove bound aromatic amines demonstrates that life began in a dye factory). The discovery of molecules containing two sulphur atoms in comet Halley leads the authors to remark that disulphide links also occur in proteins. The visual discomfort that we experience in bright sunlight suggests to them that the eye evolved in a dimmer setting "of the intensity that would be seen by a person standing on a snowfield on one of the satellites of the planet Uranus".

This book cannot be taken seriously as a work of science, but it may have other value. Hoyle made noteworthy contributions to physics and astronomy in the earlier parts of his career (though even then, his current ideas were incubating: many appear in his 1957 science-fiction novel The Black Cloud). His recent books afford full documentation of the way in which a brilliant mind can be turned to the pursuit of bizarre ideas. One clue to the mechanism is provided by the authors in this very work: "Wherever ultimate origins are concerned, one finds, not the caution and humility that common sense might suggest to be advisable, but an immense show of intellectual arrogance." $\square$

Robert Shapiro is in the Department of Chemistry, New York University, 100 Washington Square East, New York, New York 10003, USA.

\title{
Climate governed by a child
}

\section{S. G. Philander}

El Niño: Historical and Paleoclimatic Aspects of the Southern Oscillation. Edited by Henry F. Diaz and Vera Markgraf. Cambridge University Press: 1993. Pp. 476. £40, \$59.95.

UNTIL the 1940s, the climate event called El Niño, Spanish for 'The Child' (that is, Jesus), was regarded with joy in Peru and Ecuador when it occurred every few years at Christmas time. Its rains made the local deserts bloom, and the warming of the coastal waters produced treats in the form of unusual marine life. Today we perceive El Niño very differently and associate it mainly with natural disasters on a global scale: devastating floods along the coasts of Ecuador and Peru where the fishing industry is ruined by the disappearance of fish that are usually abundant; droughts in parts of Australia, South-East Asia, India and southern Africa; and unusual weather patterns worldwide, especially over the Americas. Have we changed our perception because of our greater vulnerability to climatic fluctuations? Or has the character of El Niño changed?

This book, a collection of essays by authors who have studied past El Niño episodes, shows that there has probably been little change in the nature of El Niño over the past few millennia, although there is some indication that the frequency of El Niño events increased about 5,000 years ago. Nevertheless, N. Nicholls, in describing how various Australian animals evolved to cope with prolonged droughts associated with El Niño, hints that the events have been with us for longer still. The recent change has been in our perception of El Niño, which is now a bit too gloomy: in an essay on fishery catch records, G. Sharp reminds us that Peru's lost fish are in fact Chile's gain when they reappear further south in waters that remain cold during El Niño.

Information about past El Niño episodes is available from a variety of other records: Nile flood data (that extend back to $622 \mathrm{AD}$ ), tree-ring chronologies, a 206-year record of wild land fires in the southwestern United States, pollen data, ice-core records from tropical and subtropical glaciers in the Andes and Himalayas, coral skeletons that preserve information about oceanic temperatures and salinity, and marine and lacustrine sediments. The extent to which the different records provide information about El Niño varies considerably there are many factors other than $\mathrm{El}$ Niño that affect the climate of the southwestern United States.

The book discusses these matters in detail. To specialists, the articles will be of great value. But nonspecialists may find them too technical and detailed and lacking in background material (although D. Enfield's review is readable and informative).

S. G. Philander is Director of the Program of Atmospheric and Oceanic Sciences, Princeton University, Princeton, New Jersey 08544-0710, USA.

- CUP has also recently published a paperback edition of The Earth as Transformed by Human Action: Global and Regional Changes in the Biosphere over the Past 300 Years edited by B. L. Turner II et al. $£ 27.95, \$ 39.95$. For a review, see Nature 355, 781 (1992). 